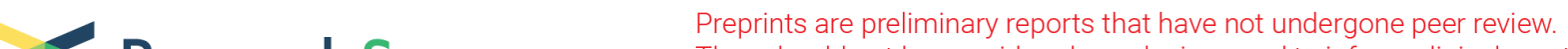 Research Square
}

\section{Genetically Encoded Dihydroxyphenylalanine Coupled with Tyrosinase for Strain Promoted Labelling}

\section{Augustine George}

CSIR-CLRI: Central Leather Research Institute CSIR https://orcid.org/0000-0002-7247-0306

Mohan Indhu

CSIR-CLRI: Central Leather Research Institute CSIR https://orcid.org/0000-0002-0943-1873

\section{Sundarapandian Ashokraj}

CSIR-CLRI: Central Leather Research Institute CSIR https://orcid.org/0000-0002-4004-6439

\section{Ganesh Shanmugam}

CSIR-CLRI: Central Leather Research Institute CSIR https://orcid.org/0000-0003-1096-4201

\section{Ponesakki Ganesan}

CSIR-CLRI: Central Leather Research Institute CSIR https://orcid.org/0000-0001-5223-419X

Numbi Ramudu Kamini

CSIR-CLRI: Central Leather Research Institute CSIR https://orcid.org/0000-0002-7097-4623

\section{A. Niraikulam ( $\square$ ayyadurai@clri.res.in )}

Central Leather Research Institute CSIR https://orcid.org/0000-0002-7333-6344

\section{Research Article}

Keywords: Protein modification, dihydroxyphenylalanine, tyrosinase, cell imaging, apoptosis

Posted Date: March 19th, 2021

DOl: https://doi.org/10.21203/rs.3.rs-296659/v1

License: (c) (i) This work is licensed under a Creative Commons Attribution 4.0 International License. Read Full License 


\section{Abstract}

Protein modifications through the genetic code engineering method have a remarkable impact on macromolecule engineering, protein translocation, protein-protein interaction, and cell biology. Here, the newly developed molecular biology approach expanding the genetic code was used for fine tuning of protein for biological availability. For that non-canonical amino acid dihydroxyphenylalanine was genetically incorporated at the defined site in the protein. Further, the congener protein was enzymatically controlled for direct conversion of quinone for strain promoted click chemistry reaction. It yields a single product with defined stereochemistry and temporally controlled conjugation with BCN. The feasibility was explored for selective cell imaging and programmed cell death in HeLa cells.

\section{Introduction}

Protein modifications through chemical and genetic methods have a remarkable impact on cell labelling, bio-conjugation studies, protein translocation, protein-protein interaction ${ }^{[1-2]}$. The chemo-selective modification of canonical amino acids on proteins had initially been executed via amide coupling of lysine [3], sulfhydryl reaction of cysteine ${ }^{[4],} \mathrm{N}$-terminal transamination ${ }^{[5]}$ and oxidative coupling of proline without alteration in the protein structure and function ${ }^{[6]}$. Most of the chemical modifications, however, have limitations of biocompatibility, regioselectivity and homogeneity ${ }^{[7]}$. Despite these challenges, in recent decades' genetic incorporation of non-canonical amino acids ${ }^{[8]}$ for protein modification has extended the possibilities of proteins for novel applications. Later, combinations of genetic code engineering and chemical methods have been employed to prepare the protein conjugates for various purposes ${ }^{[9-12]}$. Of which, metal (Cu-l) catalyzed azide-alkyne ${ }^{[13]}$ and biocompatible strain promoted oxidation-controlled click reactions were developed and used for in-vitro protein labelling, cell imaging, and immobilization. Chemo-selective modifications of proteins were also performed with specificity via an enzymatic approach for conjugating various small molecules to the proteins. Mostly, enzymemediated modifications using sortase ${ }^{[14]}$, sublitigase ${ }^{[15]}$, biotin ligase-formyl-generating enzyme $(\mathrm{FGE})^{[16]}$, and tubulin tyrosine ligase were achieved on $\mathrm{N}$ and $\mathrm{C}$-terminal tags and internal motif sequence that was appended or inserted onto the proteins ${ }^{[17]}$. The unprecedented specificity of these enzymes has enabled modification of the full-length proteins with fluorophores through expanding the genetic code.

Here, we selected tyrosine as a suitable chemical moiety for cell-selective labelling due to its hydrophobicity and propensity to form the $\pi-\pi$ stacking interaction, which causes restricted exposure of tyrosine on protein surface ${ }^{[18-19]}$. Consequently, any reactive small molecule can be conjugated to the tyrosine either through enzymatic or chemical catalyst-based methods. For instance, tyrosinase-mediated modification of tyrosine residues in the native protein was a well-established method that has been attempted for cell labelling, antibody-drug conjugates, and tagging the protein and peptides ${ }^{\text {[20-22] }}$. Enzymatic oxidation of tyrosine is a well-known multistep reaction, which results in the formation of a byproduct and inhibits the enzyme activity as well as generates toxicity. Besides, it is very difficult to maintain specificity, monitor product formation, and remove the enzyme after the reaction. Typically, 
many of the biological oxidases such as peroxidase, laccase, and polyphenol oxidase are also able to catalyze the oxidation of catechol to o-quinones but not from phenol. Among all oxidases, only tyrosinase can act upon both tyrosine and DOPA due to phenol monooxygenase and diphenoloxidase activity, respectively ${ }^{[23]}$. Hence, we aimed to combine the residue-specific incorporation of genetically encoded L-3, 4-dihydroxyphenylalanine (L-DOPA) into proteins and subsequent mild treatment of tyrosinase enzyme to tag the protein with a fluorophore. This quinone-mediated metal-free click chemistry is a useful aspect for protein labelling, in which through the enzymatic oxidation approach, ortho-quinone can be readily generated from a catechol group ${ }^{[21]}$.

Initially, the feasibility of enzyme-mediated bio-conjugation was demonstrated with a small molecule namely, L-DOPA. In principle, orthoquinone is generated from tyrosine residue by the catalytic action of tyrosinase through an intermediate-DOPA formation. However, DOPA is also a suitable substrate similar to tyrosine for enzyme recognition. To evaluate the tyrosinase-mediated modification in DOPA incorporated proteins [Annexin A5 (anX) and green fluorescent protein (GFP)], we selected highly reactive strained cyclic ring containing alkynes namely bicyclonon[6.1.0]-4-yne (BCN) and dibenzocyclooctynePEG-Fluor 545 (DBCO), which was already used in life and material science applications via StrainPromoted Azide-Alkyne Cycloaddition (SPAAC) and Strain-Promoted Oxidation-Controlled Cyclooctyne1,2-quinone Cycloaddition (SPOCQ) ${ }^{[24-27]}$. Initially, the reaction was optimized with BCN to understand the one-step SPOCQ. Then, the identical conjugation reaction was performed with DBCO to explore the selective labeling of cells and apoptosis detection (Scheme 1).

\section{Materials}

PCR reagents, $T_{4}$ DNA ligase and restriction endonucleases were obtained from Promega (Madison, $\mathrm{WI}$, USA). Isopropyl- $\beta$-D-thiogalactopyranoside (IPTG), lysozyme, L-3, 4-dihydroxyphenylalanine (L-DOPA), mushroom tyrosinase (m-tyrosinase), bicyclo[6.1.0]non-4-yne (BCN), dibenzocyclooctyne-PEG4-Fluor 545 (DBCO) and most of the chemicals required for these experiments were procured from Sigma (St. Louis, USA). The host bacterium Escherichia coli (E. coli) strain XL1-blue (Strata gene, USA) was used for plasmid DNA preparation. The nickel nitrilotriacetic acid (Ni-NTA) affinity column was purchased from clone tech (Takara Bio, USA). E. coli strain JW2581 tyrosine auxotroph was obtained from E. coli Genetic Stock Centre (Yale University, USA) and plasmid pQE-80L was obtained from Qiagen (Valencia, USA).

\section{Residue-Specific Incorporation of DOPA}

Residue specific incorporation of DOPA was carried out in the E. coli JW2581 containing PQE80L-anX and GFP vector as described by George et al [26]. The cells harboring PQE80L-anX and GFP plasmids for residue-specific incorporation was grown in LB broth containing ampicillin and were then incubated overnight at $37^{\circ} \mathrm{C}$. The cultures were collected and inoculated into $20 \%$ glucose minimal media (MM) supplemented with 20 amino acids $(40 \mathrm{mg} / \mathrm{L}), 1 \mathrm{mM} \mathrm{CaCl}_{2}, 1 \mathrm{mM} \mathrm{MgSO}_{4}$, thiamine $\mathrm{HCl}(1 \mathrm{mg} / \mathrm{mL})$ and ampicillin $(100 \mu \mathrm{g} / \mathrm{mL})$. Subsequently, cells were centrifuged at $5000 \mathrm{rpm}$ for $15 \mathrm{~min}$ and washed thoroughly in phosphate buffer saline (PBS), and further cells were inoculated into the same $20 \%$ glucose 
MM supplemented with 19 amino acids ( $40 \mathrm{mg} / \mathrm{L}$ ) except tyrosine, $0.03 \mathrm{mM}$ tyrosine and ampicillin (100 $\mu \mathrm{g} / \mathrm{mL})$. The cells were grown to mid-log phase $\left(\mathrm{OD}_{600} 0.6-0.8\right)$ at $37^{\circ} \mathrm{C}$ and $180 \mathrm{rpm}$. At this point, $1 \mathrm{mM}$ of DOPA was added in the culture flask before IPTG induction. The optimum expression of DOPA incorporated anX and GFP was achieved upon $1 \mathrm{mM} I P T G$ induction for $7 \mathrm{~h}$ at $37^{\circ} \mathrm{C}$. As a result, anXDOPA and GFP DOPA was obtained from residue-specific incorporation methods. Then, the cells were harvested and frozen at $-80^{\circ} \mathrm{C}$ until purification.

\section{Cycloaddition of BCN with DOPA}

A volume of $50 \mu \mathrm{L}$ of DOPA stock solution $(10 \mathrm{mM})$ was treated with $60 \mu \mathrm{L}$ of tyrosinase $(60 \mathrm{U})$ in Tris buffer, $\mathrm{pH} 6.8$ and mixtures were incubated at room temperature in dark condition for 5 min.

Subsequently, $100 \mu \mathrm{L}$ of 2.5 molar excess of BCN stock solution $(10 \mathrm{mM})$ in a 1:1 ratio of methanol and MilliQ (MQ) water was added to the tyrosinase treated DOPA and the reaction was carried out in dark condition at room temperature for $2 \mathrm{~h}$. Then the reaction mixture was filtered through a $0.22 \mu \mathrm{m}$ Millipore filter device (Millipore, USA). The tyrosinase treated DOPA with BCN and tyrosinase treated DOPA without BCN was subjected to UV/Vis spectroscopy.

\section{Mass Spectrometric Analysis (HR-MS)}

The same reaction mixture was lyophilized and dissolved in $1 \mathrm{~mL}$ of HPLC grade methanol and was thoroughly filtered using Millex-syringe driven filter unit. Eventually, $10 \mu \mathrm{L}$ of samples (DOPA and DOPABCN) were injected into the HR-MS (Finnigan LCQ advantage max, Thermo Fisher Scientific) equipped with a syringe pump.

\section{Preparation of anX-FITC and anX-DOPA-DBCO}

The recombinant anX-fluorescein isothiocyanate (FITC) conjugate was prepared by incubation of protein with FITC at $37^{\circ} \mathrm{C}$ in the dark for $1 \mathrm{hr}$ as described earlier [28]. Initially, $100 \mu \mathrm{g}$ of FITC was dissolved in DMSO, and it was sequentially added to $1 \mathrm{mg}$ of protein in tris buffer ( $\mathrm{pH}$ 7.4). Similarly, anX-DOPADibenzocyclooctyne-PEG4-Fluor545 (DBCO) conjugate was prepared by adding DBCO $(200 \mu \mathrm{M})$ in $1 \%$ DMSO to the anX-DOPA $(0.5 \mathrm{mg})$. This reaction was catalyzed by the addition of tyrosinase $(120 \mathrm{U})$ and incubated at $37^{\circ} \mathrm{C}$ for $2 \mathrm{~h}$. After labeling, anX-FITC and anX-DOPA-DBCO conjugate were separated from free FITC and DBCO by $10 \mathrm{kDa}$ cut-off filter (Millipore, USA). Both protein conjugates were excited using fluorescence spectrometric analysis.

\section{Nitroblue Tetrazolium (NBT) Staining Reactions}

The formation of dopaquinone and BCN conjugation after treating the DOPA containing proteins (GFPDOPA and anX-DOPA) with tyrosinase was confirmed by NBT staining. The reaction mixtures were loaded into the SDS-PAGE and the proteins were transferred on to the methanol activated polyvinylidene difluoride membrane (PVDF). Protein bands on the membrane were incubated in NBT staining solution (2 
$\mathrm{M}$ sodium glycinate, $0.24 \mathrm{mM} \mathrm{NBT}, \mathrm{pH} 10$ ) in a dark room for $3 \mathrm{~h}$. Subsequently, the membrane was washed with a sodium borate solution overnight for protein band visualization.

\section{Matrix-Assisted Laser Desorption Ionization Time of Flight (MALDI-TOF) Analysis}

The protein samples were subjected to MALDI-TOF analysis with modifications as described earlier [29]. Protein samples were desalted by a C18 zip-tip (Millipore, USA). After desalting, protein samples were examined by MALDI-TOF with a sinapinic acid matrix on a Micro flex LT instrument (Bruker Daltonik, Germany). The MALDI-TOF was operated in a linear mode to provide optimal resolution with a $25 \mathrm{kV}$ extraction voltage and $13 \mathrm{kV}$ reflectron potential.

\section{Cell lines and culture condition}

The EA.hy 926 cells were obtained from ATCC, Washington DC, USA. The cells were grown as a monolayer in Dulbecco's modified eagle medium (DMEM) high glucose supplemented with $10 \%$ Fetal Bovine Serum (FBS) and $1 \mathrm{X}$ antibiotic/antimycotic solution in humidified air with $5 \% \mathrm{CO}_{2}$ and $37^{\circ} \mathrm{C}$. The cells were cultured till 80-90\% confluence and further sub-cultured in different sized cell culture dishes/plates depending on the type of experiments.

\section{Cell viability assay with MTT}

The EA.hy 926 cells $\left(2 \times 10^{4}\right)$ were cultured in a 96 -well plate for $24 \mathrm{~h}$ before the experiment from the parent flask after trypsinization using Trypsin-EDTA solution for 2 min [30]. Different concentrations of doxorubicin hydrochloride (Doxo) was diluted using serum-free DMEM high glucose-containing $1 \mathrm{X}$ antibiotic/antimycotic solution and added with the cells for $24 \mathrm{~h}$. After the indicated treatment period, the cells were incubated for $3 \mathrm{~h}$ at $37^{\circ} \mathrm{C}$ in a culture medium containing $10 \mu \mathrm{mol} \mathrm{L}-1$ 3-(4,5-dimethylthiazol-2yl)-2,5-diphenyl tetrazolium bromide (MTT) in phosphate-buffered saline (PBS). The blue MTT formazan precipitate was then dissolved in $100 \mu \mathrm{L}$ of DMSO, and the absorbance was measured at $570 \mathrm{~nm}$ with a multi-well plate reader. The cell viability was expressed as the percentage of the absorption values in the treated cells relative to the non-treated (control) cells.

\section{Fluorescence microscopy analysis}

As described above cells were grown and Doxo $(50 \mu \mathrm{g} / \mathrm{mL})$ was used to induce apoptosis in a $100 \mu \mathrm{L}$ medium. After thetreatment, the cells were washed with 1X PBS, fixed with $4 \%$ paraformaldehyde for 10 to $15 \mathrm{~min}$ at RT and washed twice or thrice with $1 \mathrm{X}$ binding buffer. Then, the cells were incubated with 0.5 $\mu \mathrm{g} / \mathrm{mL}$ concentrations of anX-FITC and anX-DOPA-DBCO with the addition of $1 \mu \mathrm{g} / \mathrm{mL}$ of DAPI and were diluted by $1 \mathrm{X}$ binding buffer at $\mathrm{pH} 7.4$ for 15 min at RT (in dark). Thereafter, cells were then washed thrice with $1 \mathrm{X}$ binding buffer and sealed with a coverslip using glycerol mounting medium. Then, the cells were viewed by a $20 \mathrm{X}$ objective lens under an inverted fluorescence microscope (Leica DMi8, Germany) using a three-color filter and the image was analyzed by Leica Application suite 4.7 (Leica, Munich, Germany). 
As described above cells were grown and was collected by centrifugation at approximately $500 \mathrm{xg}$ for 510 mins at room temperature (RT) $\left(18-24^{\circ} \mathrm{C}\right)$ and washed by resuspending in $500 \mu \mathrm{L}$ ice cold $1 \mathrm{X}$ PBS and pelleted by centrifugation. Again, the cells were washed once with $1 \mathrm{X}$ binding buffer $(0.2 \mu \mathrm{m}$ sterilefiltered 0.1 M HEPES (pH 7.4), 1.4 M NaCl, and $25 \mathrm{mM} \mathrm{CaCl}_{2}$ solution) and were stained with anX-FITC, anX-DOPA-DBCO, anX-FITC+Propidium lodide (PI) and anX-FITC+anX-DOPA-DBCO. The staining solution was prepared as follows; Annexin V-FITC $(0.5 \mu \mathrm{g} / \mathrm{mL})$ and PI $(5 \mu \mathrm{g} / \mathrm{mL})$ were added to the $1 \mathrm{X}$ binding buffer. Cells were resuspended in $100 \mu \mathrm{L}$ of the staining solution and stained for $15 \mathrm{~min}$ at RT in the dark. Then, the cells were diluted in $1 \mathrm{X}$ binding buffer to a final volume of $400 \mu \mathrm{L}$ and analyzed for flow cytometric analysis (FCM) in BD FACS Cantoll (BD Biosciences, CA) having three color filters. The labeled cells were excited according to the reported excitation wavelength and suitable emission filters were used to detect fluorescence signals. Relative change in the fluorescence was determined by FACS-DiVa software.

\section{Results And Disscusion}

\section{Characterization of enzyme-mediated quinone reaction}

The cycloaddition reaction was carried out using dopaquinone, to confirm the catalytic action of tyrosinase towards the substrate DOPA (Fig. 1C). At first, the pertinence and hurdles of the reaction were examined at a small molecule level (DOPA). Hence, DOPA was treated with $60 \mathrm{U}$ of tyrosinase to produce dopaquinone intermediate in tris buffer $\mathrm{pH} 6.8$, which is further converted into dopachrome within a second ( $t_{1 / 2}>1 \mathrm{~s}$ ), by an intramolecular cyclization (Michael- 1,4 additions) and forms stable melanin pigment that is present in the skin, hair and eyes of all animals ${ }^{[31-32]}$. As reported by Dukler et al, we also observed a similar absorption spectrum peak corresponding to dopachrome at $475 \mathrm{~nm}$, as a consequence of tyrosinase catalysis (Fig. 1D-1). The conversion of DOPA to dopachrome does not lead to a reduction in the absorbance but leads to a gradual shift in the absorption spectrum [33]. In contrast, a sharp absorbance reduction, a straight line in the UV-Visible spectral region (200-600 nm) was obtained after the tyrosinase treated DOPA conjugated with BCN (Fig. 1D-1), denoting that the reaction is stabilized after the addition of BCN. The absorbance of tyrosinase treated DOPA was compared with BCN conjugated dopaquinone that provided the relative amount of DOPA conjugated with BCN. The conjugation efficiency between dopaquinone and BCN was discovered to be around $>90 \%$, which was determined by measuring the difference in the intensity of absorbance maxima at $475 \mathrm{~nm}$ before and after BCN conjugation. This data illustrated that the in situ generated quinone through enzymatic catalysis rapidly reacts with the triple bond of the strained alkyne $(\mathrm{BCN})$ via inverse electron demand Diels-Alder cycloaddition, which is sufficient for the generation of DOPA-BCN conjugate. DOPA conjugation was also confirmed by HR-MS analysis with expected molecular mass for DOPA (198.07 $\mathrm{m} / \mathrm{z}$ ) (Fig. 1D-2) and BCN functionalized dopaquinone (355.18 m/z) (Fig. 1D-3). As a positive control experiment, tyrosine was also subjected to tyrosinase treatment and $B C N$ conjugation (Fig. 1A), which also yielded similar results as DOPA (Fig.1B.1-3). These results assured that the formation of 
dopachrome through intramolecular Michael- 1, 4 additions could be controlled within a short period (10 min) by the addition of BCN.

\section{Biosynthesis of DOPA incorporated protein and purification}

To probe the in vivo expression of DOPA incorporated proteins, we selected GFP and anX having different numbers of surface-exposed tyrosine residues. Before proceeding with the protein expression studies, tyrosine residues that are located at the protein's (anX and GFP) surface was perceived by extricating a 3D model structure from PDB (Fig. 2A-B). Consequently, through the energy minimization process in the protein modeling, it was predicted that anX has six tyrosine residues (Y94, Y133, Y148, Y256, Y2 57 and Y297) on the surface, out of 11 residues. GFP has eight tyrosine residues including chromophore Y66. Out of these 8 residues, 5 residues (Y92, Y151, Y182, Y200 and Y273) are surface exposed, Y143 is partially surface exposed and $\mathrm{Y} 74$ is buried internally (GFP and anX sequence information is provided in the supporting information). Next, to perform the tyrosinase catalysed bio-conjugation reaction on DOPA incorporated proteins, GFP and anX were cloned and the expression was optimized in an E. coli strain JW2581 using 1 mM IPTG ${ }^{[34]}$. Simultaneously, DOPA was introduced into the proteins (GFP and anX) through the mis-aminoacylation method after depleting the amino acid tyrosine ${ }^{[35]}$. The expression efficiency of GFP-DOPA and anX-DOPA was compared to native proteins via $12 \%$ SDS-PAGE analysis (Fig. 2C). The protein with the substitution of DOPA did not significantly alter the expression of proteins at 37

${ }^{\circ} \mathrm{C}$. Further, the protein purification was achieved by the Ni-NTA affinity column and was desalted using AKTA Explorer FPLC (Fig. S2). The incorporation efficiency of DOPA in anX was measured and was compared with wild-type proteins by MALDI-TOF analysis (Fig. 2D). The mass of the GFP increased from $28267 \mathrm{Da}$ to $28396 \mathrm{Da}$ on DOPA incorporation (data not shown), and the mass of anX increased from $35937 \mathrm{Da}$ to $36129 \mathrm{Da}$, indicating the incorporation efficiency of $>98 \%$.

\section{Structural and Functional Characterization of Modified proteins}

To resolve the secondary structure of proteins after DOPA incorporation, the protein samples (GFP and anX) were subjected to CD analysis. Typically, GFP is a beta-sheet protein, showing the positive and negative bands at 195 and $218 \mathrm{~nm}$, respectively whereas anX predominantly has alpha-helix with a negative deflection at around $222 \mathrm{~nm}$ and $208 \mathrm{~nm}$ (Fig. 2E, and S3). These two proteins have retained secondary structure with a characteristic beta-sheet and alpha-helix pattern after DOPA incorporation. The functional property of these modified proteins viz., GFP-DOPA and anX-DOPA was also evaluated through fluorescent spectroscopic and direct FITC-cell labeling studies, respectively. From these studies, it was demonstrated that GFP-DOPA could maintain its functional property by emitting the orange fluorescence at $525 \mathrm{~nm}$ due to the presence of DOPA at the Y66 position of chromophore forming peptide (Fig. S3.B) and anX-DOPA was able to bind to phosphotidyl serine in the lipid membrane of apoptotic cells (Fig. 4C).

\section{Coupling mechanism in protein for cell labeling}


To establish a protein-based cell labeling method, the tyrosinase-mediated modification was explored on DOPA incorporated proteins (GFP and anX). In principle, the formation of a quinone from tyrosine by enzymatic and chemical methods is one of the rapid reactions that non-specifically create covalent crosslinking. This is due to the electrophilic quinone that is readily attacked by the proximate nucleophiles especially lysine, histidine and cysteine residues in the protein via Michael type additions ${ }^{[36]}$. Earlier FREMY'S SALT was tested for the direct conversion of tyrosine to Dopaquinone without the formation of any intermediate. The chemical oxidant-mediated conversion of tyrosine to dopaquinone requires a longer incubation time $(20 \mathrm{~h})$ and a high concentration of FREMY'S salt (10M excess) for polymerization, Intra cross-linking of proteins and peptides and conjugation of fluorophore ${ }^{[26-37]}$. Secondly, FREMY'S SALT is a strong oxidant, hence it could polymerize, aggregate and precipitate the protein. In such a condition, natural enzyme tyrosinase is necessary for reducing the limitations of oxidants like FREMY'S Salt ${ }^{[37]}$. Usually, chemoselective conjugation for proteins are primed on surface-exposed residues in a suitable reaction condition since it provides high selectivity and accessibility of enzymes towards the least distributed tyrosine residues on the surface. Dopaquinone product formation in proteins was optimized by incubating the DOPA incorporated protein $(0.5 \mathrm{mg})$ with $120 \mathrm{U}$ of tyrosinase in Tris buffer pH 6.8 (Fig. 3A). At this $\mathrm{pH}$, the degree of polymerization and cross-linking that is mediated by a free amino group in the lysine residues is prevented ${ }^{[38]}$. To substantiate the dopaquinone formation in proteins, a redox staining assay was executed using NBT, for which tyrosinase treated samples were transferred onto PVDF membrane after SDS-PAGE. As a result, purple color owing to the redox cycling of dopaquinone and polymerization (shearing of proteins) was observed on the membrane, which corroborates the conversion of DOPA incorporated protein into quinoprotein by the action of tyrosinase [39] (Fig. 3B.4). Further, residue-specific modification of anX-DOPA was supported by mass spectrometry (MALDI-TOF) with the expected mass shift (36129 Da) (Fig. 2D). Our results reinforced the previous statement on DOPA modification to produce quinone in a single step and it was identified that 1, 2quinones could quickly react with $\mathrm{BCN}$ as described earlier ${ }^{[7]}$. Therefore, we aimed to functionalize BCN with DOPA incorporated proteins by mild stirring for $2 \mathrm{~h}$ at RT. After dialysis, BCN functionalized anXDOPA was confirmed by SDS-PAGE (Fig. 3B.3) and MALDI-TOF analysis with anticipated mass shift (37071 Da) (Fig. 3B.1), representing that five molecules of BCN would have reacted with enzyme catalysed-anX-DOPA. The suitability of the reaction for residue-specific labeling was inspected and were allowed to conduct a SPOCQ on quino-proteins. The anX-DOPA was coupled with a strained alkyne namely fluorophore DBCO by the action of the enzyme tyrosinase and analyzed by SDS-PAGE (Fig. S4) and MALDI-TOF analysis with a mass shift (40808 Da) indicating that five molecules of DBCO is conjugated with surface-exposed DOPA residues of anX-DOPA (Fig. 3B.2). Moreover, tyrosinase catalyzed anX-DOPA-DBCO conjugate exhibited emission spectrum at $595 \mathrm{~nm}$ after dialysis (10 kDa), which shows that the anX-DOPA was tagged with the fluorophore (DBCO) (Fig. 3C). In contrast, anX-DOPA-DBCO was also prepared as a control experiment without tyrosinase, which did not exhibit fluorescence when it was exposed to UV light after the dialysis (Fig. 3C.1-3). It denotes the importance of tyrosinase for residuespecific protein modification and its key role in labeling experiments. The generality of this method can be applied to any proteins containing fewer numbers of surface-exposed tyrosine residues. To test the 
application of fluorogenically labeled quino-protein, we employed the single-step strain-promoted oxidation-controlled click reactions for cell labeling and imaging experiments. Hence, the fluorogenically labeled anX-DOPA was used for apoptosis recognition.

\section{Fluorescent microscopy and flow cytometry analysis of apoptotic EA.hy 926 cells}

During programmed cell death or apoptosis, the cell loses the phospholipid asymmetry of the plasma membrane, which reshuffles phosphatidylserine (PS) from its usual position ${ }^{[40]}$. In the presence of $\mathrm{Ca}^{2+}$, the protein anX exclusively and sturdily binds with the PS molecule. Therefore, commercially available fluorescent tags such as FITC, Oregon-Green, or Alexa Fluor 488, succinimidyl esters were linked with anX by chemical coupling methods and they were extensively applied to probe apoptosis incidence. However, the classical coupling reactions cannot be controlled due to the presence of the free amino group in the lysine residues, which are mostly surface exposed and exist predominantly in or near the Phosphatidylserine binding pocket.

The consequent conjugation of Annexin with FITC would probably result in fluorescence quenching and yield a heterogeneous mixture ${ }^{[41-42]}$. The added advantage of genetic code engineering is to develop a highly controlled and homogenously labeled fluorescent anX conjugate without altering its functional property. To evaluate the efficacy of anX-DOPA-DBCO for cell labeling, apoptotic studies were done in EA.hy926 cells. Apoptosis was induced in EA.hy 926 cells by treating with Doxo, and the apoptotic changes were observed using phase-contrast microscopy. Cells with flattened and disruptive membrane morphology were observed at the concentration of $50 \mu \mathrm{g} / \mathrm{mL}$ Doxo (Fig. 3D). The PS-binding activity of anX-DOPA-DBCO was analyzed on apoptotic EA.hy 926 cells through flow cytometry. It was compared with the commonly accessible anX-FITC. $0.5 \mu \mathrm{g} / \mathrm{mL}$ concentration of anX-FITC and anX-DOPA-DBCO were used to stain the apoptotic cells (Fig. 4B-C) and it was compared to the cells without apoptosis induction (Fig. 4A). The cells treated with anX-DOPA-DBCO responded well for apoptosis and it was more or less similar to anX-FITC, which indicated that apoptotic labeling using anX-DOPA-DBCO resulted in PS binding even after protein modification (Fig. 4B-D).

Moreover, the advantage of using DBCO (orange fluorophore) over FITC is that it has low quantum yield but high emission maxima, lower light scattering, and reduced autofluorescence ${ }^{[43]}$. FITC (shorter wavelength) with green spectral window is much more energetic than DBCO (longer wavelength) with red spectral window, as a result, shorter wavelength fluorophores including FITC, DAPI, Alexa-488 has potential photo-bleaching, lesser photo-stability and $\mathrm{pH}$ sensitivity in comparison with the light of longer wavelength orange and red fluorophores (DBCO) ${ }^{[44]}$. From our results, we postulated that tyrosinasemediated modification in anX-DOPA did not alter the function of proteins, especially for apoptosis detection. Though it is too preliminary, however, it could pave a way to extend the single-step strain promoted oxidation-controlled click reactions via expanding the genetic code to the other caspase pathway proteins such as Bax and Bcl-XL, which are involved in the early and late events of apoptosis.

\section{Conclusion}


In this study, we developed a biorthogonal accelerated tyrosinase-mediated strain-promoted oxidative approach for cell labeling, which needed an easily reactive quinone functional moiety. This was achieved through the incorporation of DOPA in proteins and ensue a single product formation. Most significantly, this method could be used for various applications apart from generating protein conjugates. It can also be applied for targeted drug delivery and proteins for tagging cellular functions. This is one of the promising facile conjugation approaches, in particular, for cell labeling and apoptosis detection.

\section{Declarations}

\section{Compliance with ethical standards}

Conflict of Interest The authors declare that they have no conflict of interest.

Ethical approval This article does not contain any studies conducted on human or animal subjects. Hence, no ethics approval was required for this study.

\section{Authors Contribution}

All authors contributed to the study conception and design. Among them NA, AG and MI conceived the project and wrote the paper; $A G, M I$ and SA performed the experiments and analyzed the data; $G S, P G$ and NRK contributed to analyses and interpretation of data. All authors have read and agreed to the published version of the manuscript.

\section{References}

1. Rabuka D, Rush JS, Gregory WD, Wu P, Bertozzi CR (2012) Site-specific chemical protein conjugation using genetically encoded aldehyde tags. Nat Protoc 7:1052-1067

2. Gao X, Wu H, Lee KC, Liu H, Zhao Y, Cai Z, Jiang Y (2012) Stable isotope N-phosphorylation labeling for peptide de novo sequencing and protein quantification based on organic phosphorus chemistry. Anal Chem 84:10236-10244

3. Kuo YH, Konopko AM, Borotto NB, Majmudar JD, Haynes SE, Martin BR (2017) Profiling protein Ssulfination with maleimide-linked probes. ChemBioChem 18:2028-2032

4. Chung HS, Wang SB, Venkatraman V, Murray Cl, Van Eyk JE (2013) Cysteine oxidative posttranslational modifications: emerging regulation in the cardiovascular system. Circ Res 112:382-392

5. Witus LS, Netirojjanakul C, Palla KS, MuehI EM, Weng CH, lavarone AT, Francis MB (2013) Sitespecific protein transamination using $\mathrm{N}$-methylpyridinium-4-carboxaldehyde. J Am ChemSoc 135:17223-17229

6. Spicer CD, Davis BG (2014) Selective chemical protein modification. Nat Commun 5:1-14

7. Borrmann A, Fatunsin O, Dommerholt J, Jonker AM, Lowik DW, van Hest JC, van Delft FL. Strainpromoted oxidation-controlled cyclooctyne-1, 2-quinone cycloaddition (SPOCQ) for fast and 
activatable protein conjugation. BioconjugateChem 2015, 26: 257-261

8. Nodling AR, Spear LA, Williams TL, Luk LY, Tsai YH (2019) Using genetically incorporated unnatural amino acids to control protein functions in mammalian cells. Essays Biochem 63:237-266

9. Ayyadurai N, Prabhu NS, Deepankumar K, Jang YJ, Chitrapriya N, Song E, Lee N, Kim SK, Kim BG, Soundrarajan N, Lee S, Cha HJ, Budisa N, Yun H (2011) Bioconjugation of I-3,4-

Dihydroxyphenylalanine Containing Protein with a Polysaccharide. Bioconjugate Chem 22:551-555

10. Saxon E, Armstrong JI, Bertozzi CR (2000) A "traceless" Staudinger ligation for the chemoselective synthesis of amide bonds. Org 2:2141-2143

11. Wang Q, Chan TR, Hilgraf R, Fokin VV, Sharpless KB, Finn MG (2003) Bioconjugation by copper (I)catalyzed azide-alkyne [3 + 2] cycloaddition. J Am Chem 125:3192-3193

12. Agard NJ, Prescher JA, Bertozzi CR (2004) A strain-promoted [3 + 2] azide - alkyne cycloaddition for covalent modification of biomolecules in living systems. J Am ChemSoc 126:15046-15047

13. Meldal M, Diness F (2020) Recent fascinating aspects of the CuAAC click reaction. TrendsChem 2:569-584

14. Mazmanian SK, Liu G, Ton-That H, Schneewind O (1999) Staphylococcus aureus sortase, an enzyme that anchors surface proteins to the cell wall. Science 285:760-763

15. Chang TK, Jackson DY, Burnier JP, Wells JA (1994) Subtiligase: a tool for semisynthesis of proteins. Proc Natl AcadSci 91:12544-12548

16. Miyao H, Ikeda Y, Shiraishi A, Kawakami Y, Sueda S (2015) Immobilization of immunoglobulin-Gbinding domain of protein $A$ on a gold surface modified with biotin ligase. Anal Biochem 484:113121

17. Nguyen SS, Prescher JA (2020) Developing bioorthogonal probes to span a spectrum of reactivities. Nat Rev Chem 4:476-489

18. McGaughey GB, Gagné M, Rappé AK (1998) $\pi$-stacking interactions: alive and well in proteins. J BiolChem 273:15458-15463

19. Struck AW, Bennett MR, Shepherd SA, Law BJ, Zhuo Y, Wong LS, Micklefield J (2016) An enzyme cascade for selective modification of tyrosine residues in structurally diverse peptides and proteins. $J$ Am ChemSoc 138:3038-3045

20. Long MJ, Hedstrom L. Mushroom Tyrosinase Oxidizes Tyrosine-Rich Sequences to Allow Selective Protein Functionalization. ChemBioChem 2012, 13: 1818-1825

21. Bruins JJ, Westphal AH, Albada B, Wagner K, Bartels L, Spits H, van Berkel WJ, van Delft FL. Inducible, site-specific protein labeling by tyrosine oxidation-strain-promoted $(4+2)$ cycloaddition. BioconjugateChem 2017, 28: 1189-1193

22. Marmelstein AM, Lobba MJ, Mogilevsky CS, Maza JC, Brauer DD, Francis MB (2020) TyrosinaseMediated Oxidative Coupling of Tyrosine Tags on Peptides and Proteins. J Am ChemSoc 142:50785086 
23. Ito S, Sugumaran M, Wakamatsu K (2020) Chemical reactivities of ortho-quinones produced in living organisms: Fate of quinonoid products formed by tyrosinase and phenoloxidase action on phenols and catechols. Int J MolSci 21:6080

24. Borrmann A, Fatunsin O, Dommerholt J, Jonker AM, Lowik DW, van Hest JC, van Delft FL. Strainpromoted oxidation-controlled cyclooctyne-1, 2-quinone cycloaddition (SPOCQ) for fast and activatable protein conjugation.BioconjugateChem 2015, 26: 257-261

25. Chen X, Wu YW (2016) Selective chemical labeling of proteins. Org BiomolChem 14:5417-5439

26. George A, Krishna Priya G, llamaran M, Kamini NR, Ganesh S, Easwaramoorthi S, Ayyadurai N. Accelerated Strain-Promoted and Oxidation-Controlled Cyclooctyne-Quinone Cycloaddition for Cell Labeling. ChemistrySelect 2017, 2: 7117-7122

27. Kim E, Koo H (2019) Biomedical applications of copper-free click chemistry: in vitro, in vivo, and ex vivo. ChemSci 10:7835-7851

28. Boersma AW, Nooter K, Oostrum RG, Stoter G (1996) Quantification of apoptotic cells with fluorescein isothiocyanate-labeled annexin $\mathrm{V}$ in chinese hamster ovary cell cultures treated with cisplatin. Cytometry 24:123-130

29. Shevchenko A, Tomas H, Havli J, Olsen JV, Mann M (2006) In-gel digestion for mass spectrometric characterization of proteins and proteomes. Nat protoc 1:2856-2860

30. Li D, Zhang RZ, Shi HX, Yang YH, Tian T, Wang L (2019) Melanocyte spheroids are formed by repetitive long-term trypsinization. Indian J DermatolVenereolLeprol 85:258-265

31. Zecca L, Bellei C, Costi P, Albertini A, Monzani E, Casella L, Gallorini M, Bergamaschi L, Moscatelli A, Turro NJ, Eisner M (2008) New melanic pigments in the human brain that accumulate in aging and block environmental toxic metals. Proc Natl AcadSci 105:17567-17572

32. Dukler S, Wilchek M, Lavie D (1971) Oxidation of tyrosine and its peptides with potassium nitrosodisulphonate. Tetrahedron 27:607-614

33. Kim JH, Jang DH, Lee KW, Kim KD, Shah AB, Zhumanova K, Park KH (2020) Tyrosinase Inhibition and Kinetic Details of PuerolA Having But-2-Enolide Structure from Amorphafruticosa. Molecules 25:2344

34. Sambrook J, Fritsch EF, Maniatis T (1989) Molecular cloning: a laboratory manual, 2nd edn. Cold Spring Harbor Laboratory, Cold Spring Harbor

35. Moor N, Klipcan L, Safro MG (2011) Bacterial and eukaryotic phenylalanyl-tRNAsynthetases catalyze misaminoacylation of tRNAPhe with 3, 4-dihydroxy-L-phenylalanine. ChemBiol 18:1221-1229

36. Lee BP, Messersmith PB, Israelachvili JN, Waite JH (2011) Mussel-inspired adhesives and coatings. AnnuRev Mater Res 41:99-132

37. Wilchek M, Miron T (2015) Mussel-inspired new approach for polymerization and cross-linking of peptides and proteins containing tyrosines by Fremy's salt oxidation. Bioconjugatechem 26:502-510

38. Burzio LA, Waite JH (2000) Cross-linking in adhesive quinoproteins: studies with model decapeptides. Biochemistry 39:11147-11153 
39. Paz MA, Flückiger R, Boak A, Kagan HM, Gallop PM (1991) Specific detection of quinoproteins by redox-cycling staining. J BiolChem 266:689-692

40. Bratton DL, Fadok VA, Richter DA, Kailey JM, Guthrie LA, Henson PM (1997) Appearance of phosphatidylserine on apoptotic cells requires calcium-mediated nonspecific flip-flop and is enhanced by loss of the aminophospholipid translocase. J BiolChem 272:26159-26165

41. Ernst JD, Mall A, Chew G (1994) Annexins possess functionally distinguishable Ca2 + and phospholipid binding domains. BiochemBiophys Res 200:867-876

42. Ernst JD, Yang L, Rosales JL, Broaddus VC (1998) Preparation and characterization of an endogenously fluorescent annexin for detection of apoptotic cells. Anal Biochem 260:18-23

43. Shcherbakova DM, Subach OM, Verkhusha VV (2012) Red fluorescent proteins: advanced imaging applications and future design. AngewChemlnt Ed 51:10724-10738

44. Jacobson K, Derzko Z, Wu ES, Hou Y, Poste G (1976) Measurement of the lateral mobility of cell surface components in single living cells by fluorescence recovery after photobleaching. $J$ SupramolStruct 5:565-576

\section{Figures}


A<smiles>NC(Cc1ccc(O)cc1)C(=O)O</smiles><smiles>NC(Cc1ccc(O)c(OCC(=O)O)c1)C(=O)O</smiles><smiles>C=C(C)C(C)CC1=CC=CC(=O)C1=O</smiles>

Dopaquinone

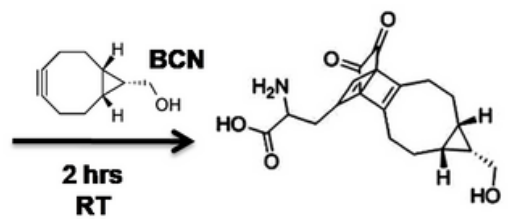

Quinone Cycloaddition

B
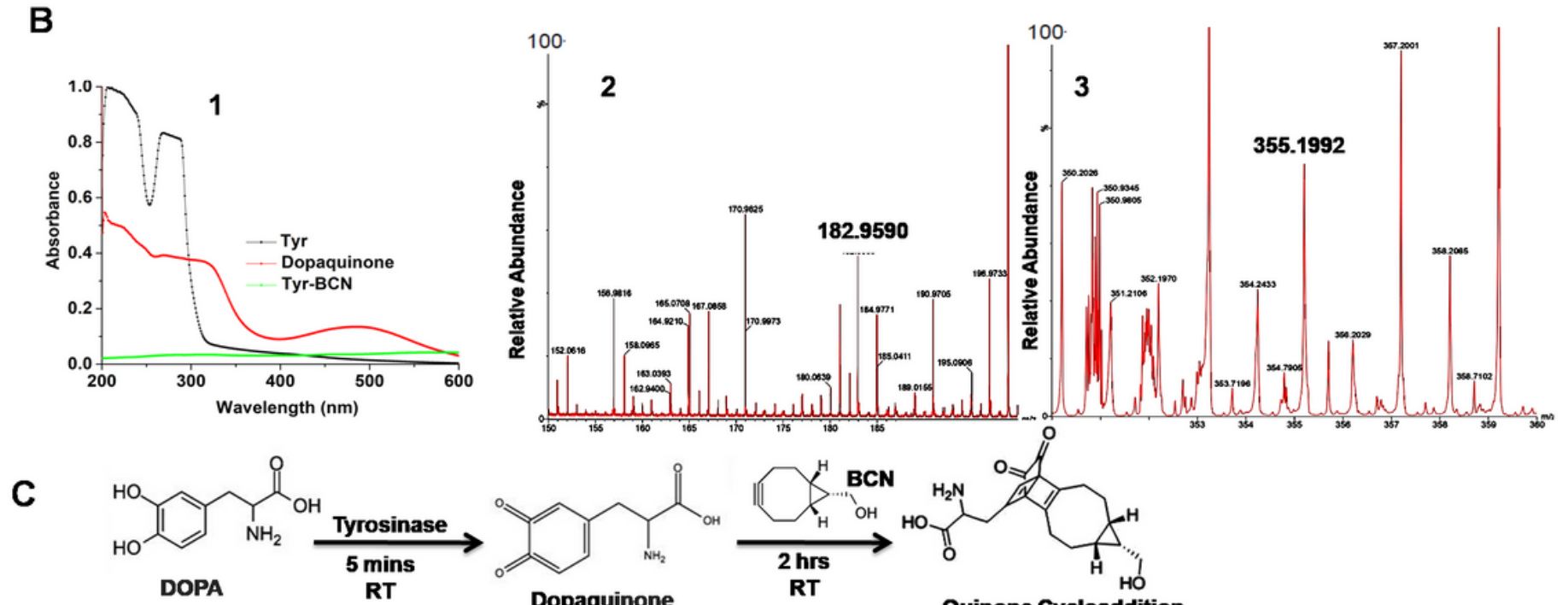

D
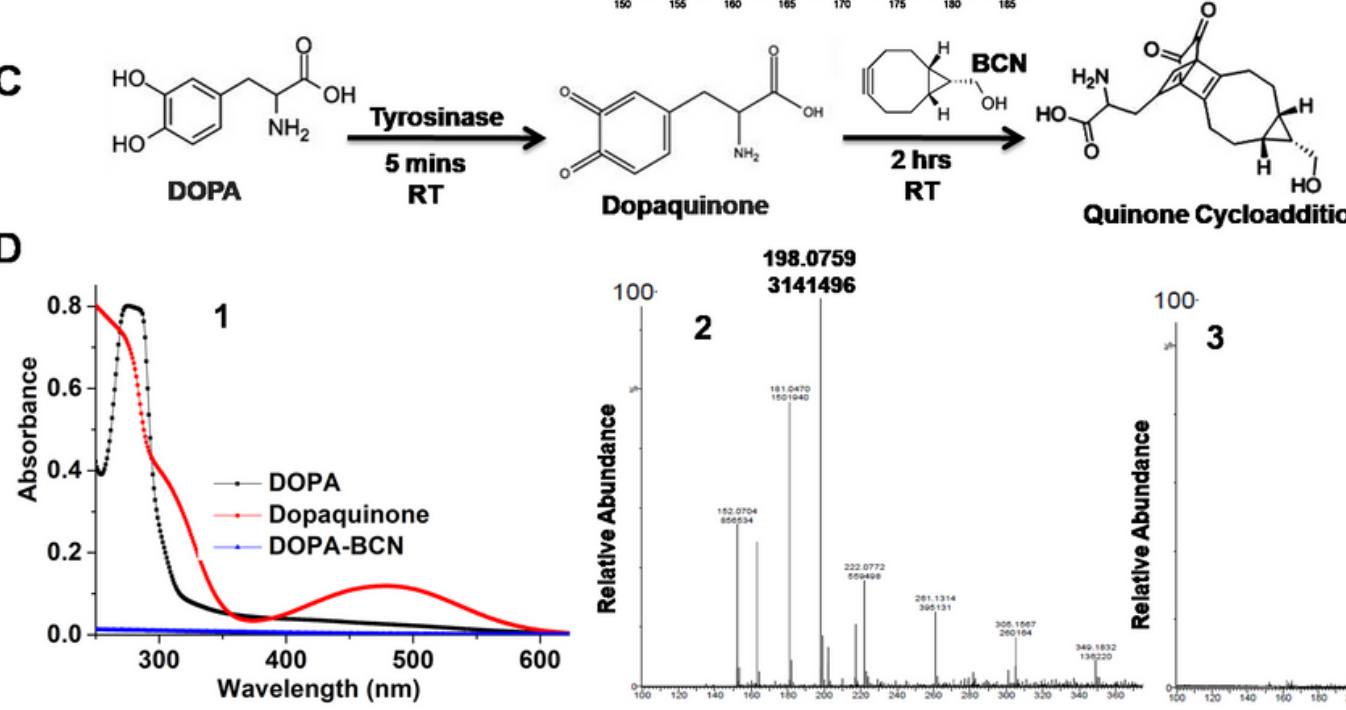

Quinone Cycloaddition
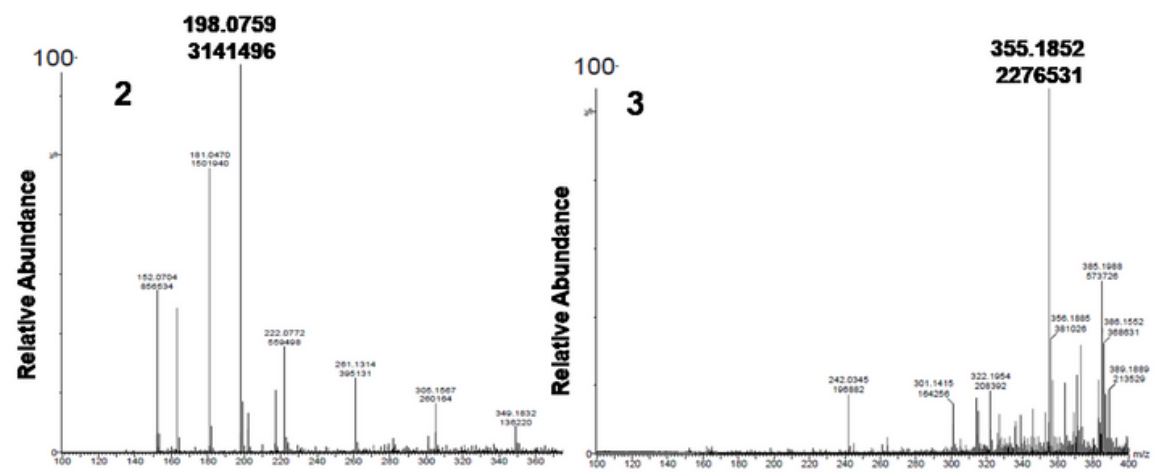

Figure 1

Characterization of enzyme-mediated quinone reaction using UV spectroscopy analysis and HighResolution Mass Spectrometry (HR-MS). A) Schematic representation of quinone formation from tyrosine and click reaction with BCN as a control. B) (1) The absorbance spectrum of dopaquinone at $475 \mathrm{~nm}$ by the enzyme tyrosinase with tyrosine and reduction of absorbance spectra after product formation (TyrBCN), (2) The HR-MS analysis of Tyr and (3) Tyr-BCN product formation. C) Schematic representation of quinone formation from DOPA and click reaction with BCN. D) (1) The absorbance spectrum of dopaquinone at $475 \mathrm{~nm}$ by the enzyme tyrosinase with DOPA and reduction of absorbance spectra after product formation (DOPA-BCN), (2) The HR-MS analysis of DOPA and (3) DOPA-BCN product formation. 


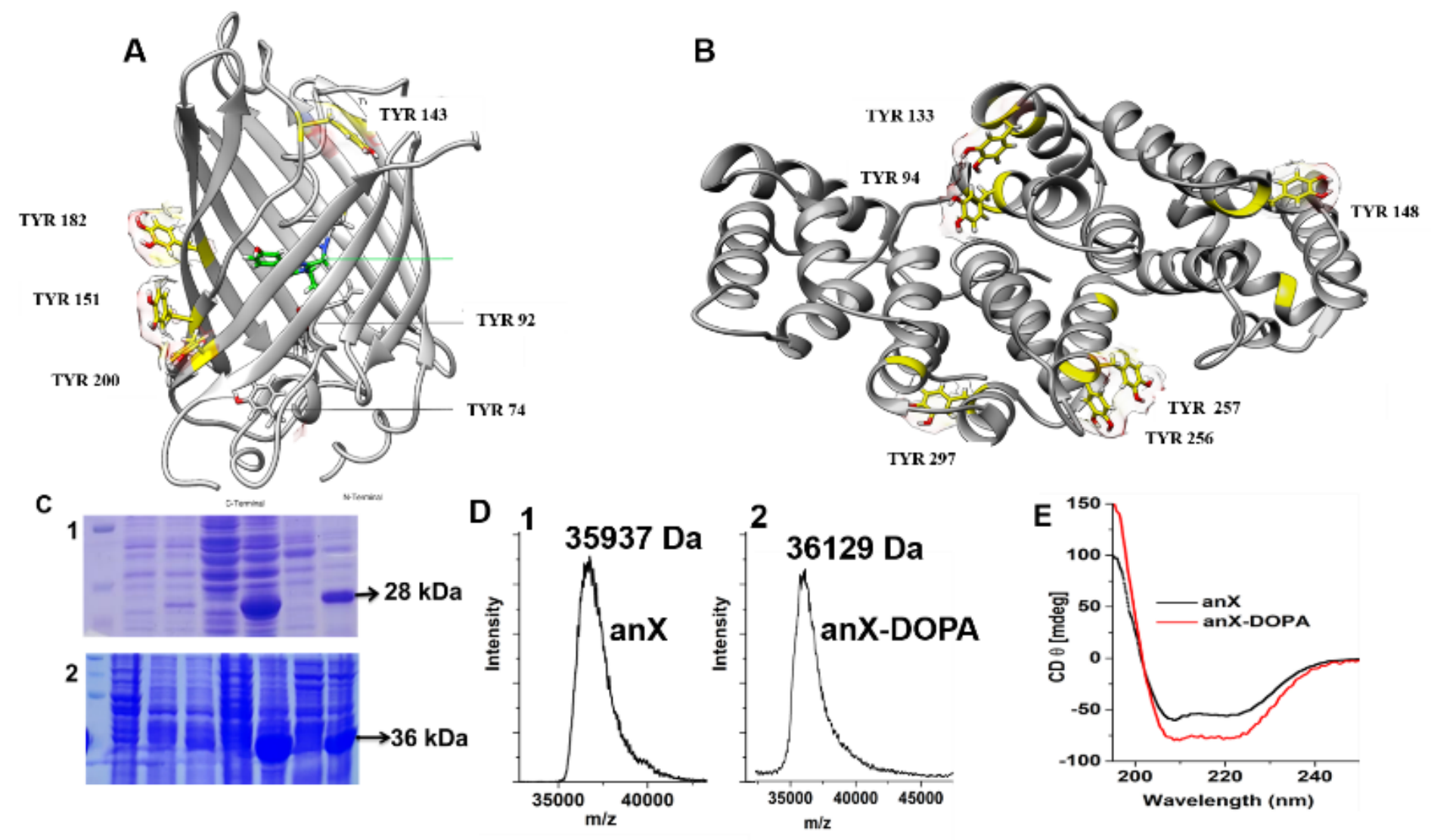

Figure 2

3-D structure of GFP (A) and anX (B), which shows the surface exposed tyrosine residues. (C) The protein expression profile of GFP and GFP-DOPA, M: Protein Marker, 1: GFP without IPTG (-Tyrosine), 2: GFP with IPTG (-Tyrosine), 3: GFP without IPTG (+Tyrosine), 4: GFP with IPTG +Tyrosine, 5: GFP without IPTG (+DOPA), 6: GFP with IPTG (+DOPA). MALDI-TOF analysis of GFP (D) and GFP-DOPA (E). (F) The protein expression profile of anX and anX-DOPA, M: Protein Marker, 1: E. coli tyrosine auxotroph, 2: anX without IPTG (-Tyrosine), 3: anX with IPTG (-Tyrosine), 4: anX without IPTG (+Tyrosine), 5: anX with IPTG (+Tyrosine), 6: anX without IPTG (+DOPA), 7: anX with IPTG (+DOPA). MALDI-TOF analysis of anX (G) and anX-DOPA $(H)$. Circular dichroism analysis of $(I)$, and anX and anX-DOPA. 
A
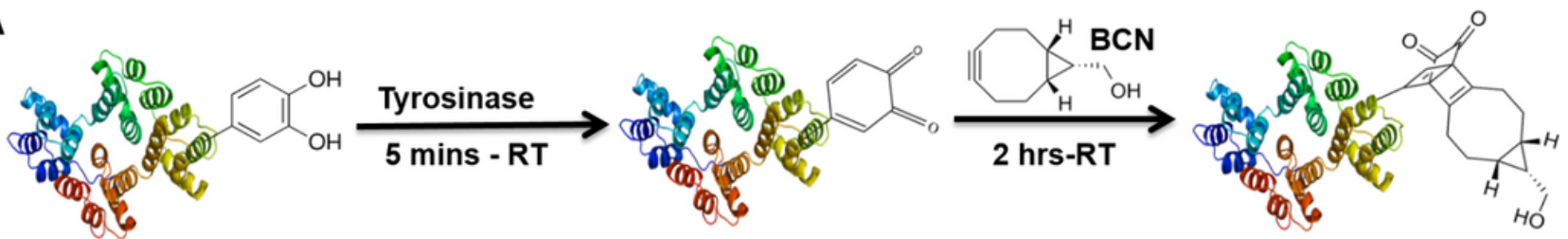

Protein with DOPA

Quinone formation in Protein

Quinone mediated cycloaddition in protein
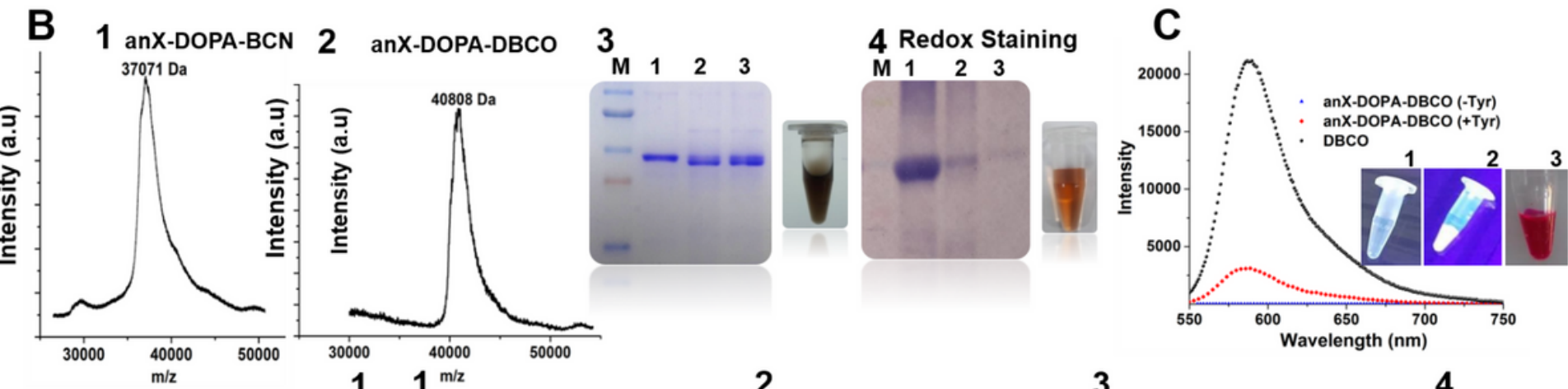

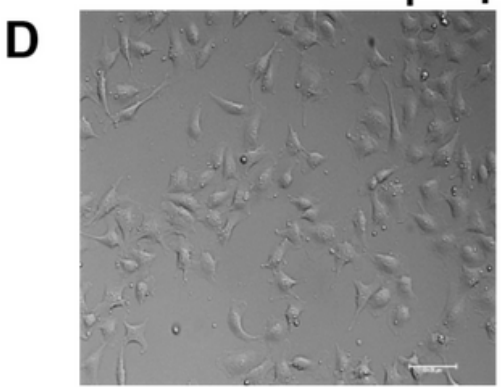

Control

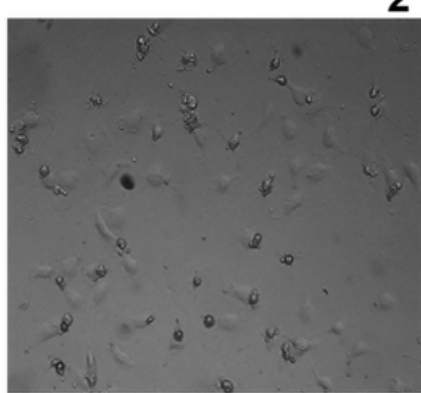

$10 \mu \mathrm{g} / \mathrm{ml}$

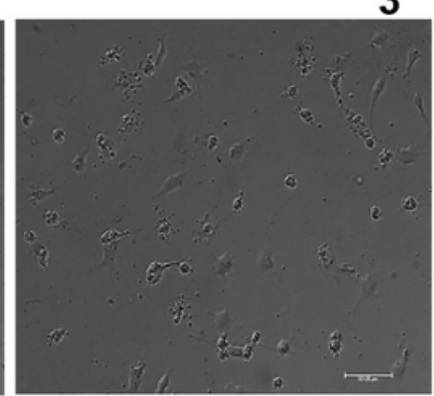

$20 \mu \mathrm{g} / \mathrm{ml}$
4

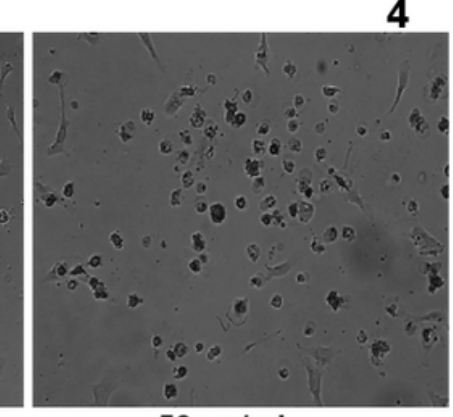

$50 \mu \mathrm{g} / \mathrm{ml}$

\section{Figure 3}

Coupling mechanism in protein for cell labeling. A) Schematic representation of protein encoded with DOPA treated with enzyme and subsequently attached with BCN. B) Confirmation analysis of (1) BCN functionalized anX-DOPA (37071 Da) and (2) DBCO functionalized anX-DOPA (40808 Da) by MALDI-TOF analysis, (3) SDS-PAGE (M: Protein Marker, 1: anX-DOPA, 2: tyrosinase treated anX-DOPA, 3: anX-DOPA functionalized by BCN via tyrosinase), and (4) Redox staining (M: Protein Marker, 1: anX-DOPA, 2: tyrosinase treated anX-DOPA, 3: anX-DOPA functionalized by BCN via tyrosinase). C) Fluorescent spectroscopic analysis of tyrosinase catalysed anX-DOPA-DBCO (red color), anX-DOPA-DBCO without tyrosinase (blue colour-straight line) and DBCO alone (black color). (1) anX-DOPA-DBCO without tyrosinase, (2) anX-DOPA-DBCO with tyrosinase and (3) DBCO alone. D) Cell viability was checked with different concentrations of Doxo in EA.hy926 cells. 


\section{A}
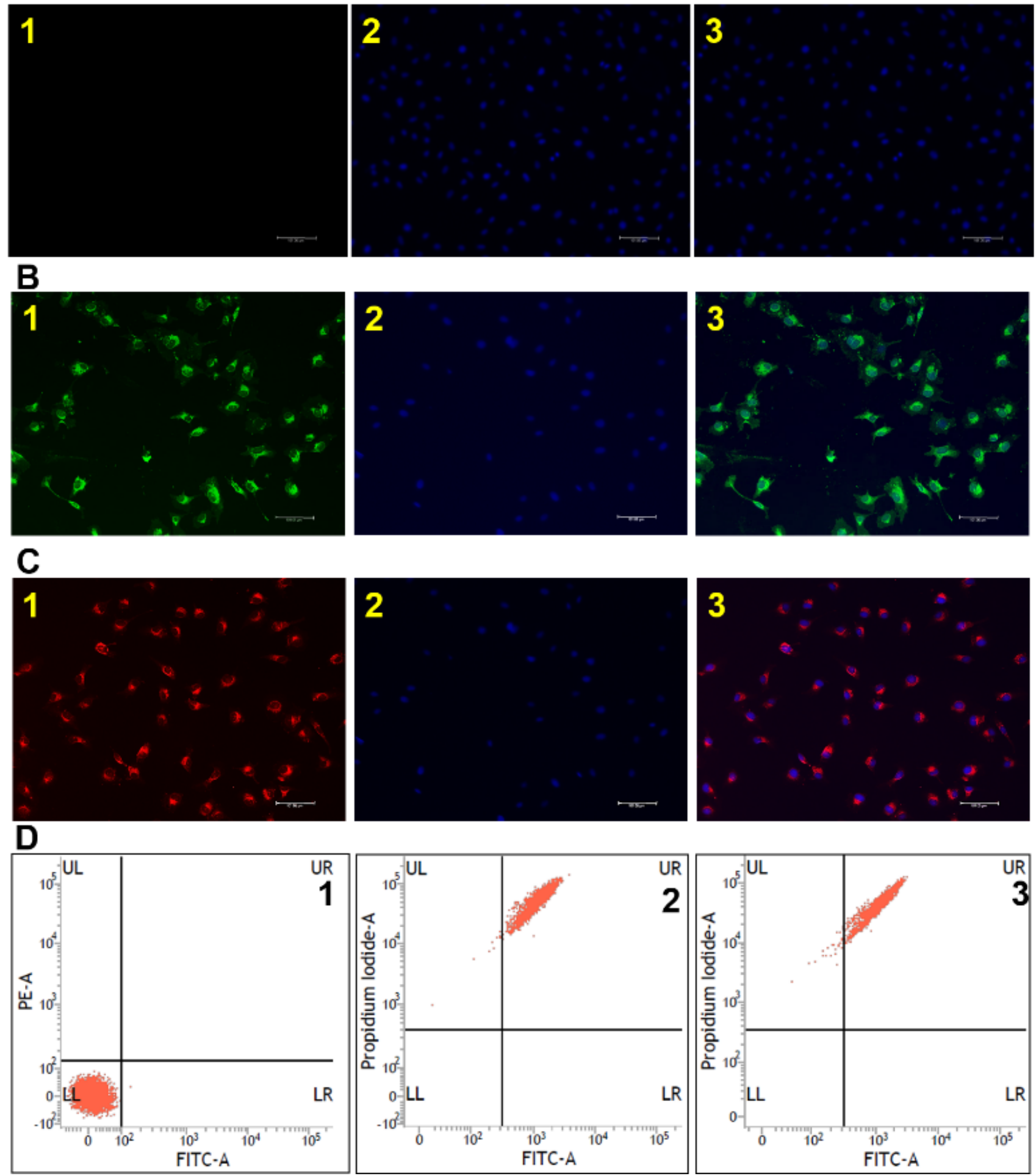

\section{Figure 4}

Fluorescent microscopy and flow cytometry analysis of apoptotic EA.hy 926 cells. Fluorescence microscopic analysis of A) Cells without apoptosis induction; (1) stained with $0.5 \mu \mathrm{g} / \mathrm{mL}$ anX-DOPADBCO, (2) $1 \mu \mathrm{g} / \mathrm{mL}$ DAPI (blue), (3) stained with anX-DOPA-DBCO/DAPI. (B-C) Staining of EA. hy 926 cells with apoptosis induction. B) anX-FITC detection of apoptosis; Fluorescence microscopic analysis of 0.5 $\mu \mathrm{g} / \mathrm{mL}$ anX-FITC (positive control-green) (1), $1 \mu \mathrm{g} / \mathrm{mL}$ DAPI (blue) (2) and anX-FITC/DAPI (3). C) anX- 
DOPA-DBCO detection of apoptosis; Fluorescence microscopic analysis of $0.5 \mu \mathrm{g} / \mathrm{mL}$ anX-DOPA-DBCO (red) (1), $1 \mu \mathrm{g} / \mathrm{mL}$ DAPI (blue) (2) and anX-DOPA-DBCO/DAPI (3) staining of EA.hy 926 cells after a 24hour treatment. D) Dot plot of Doxo treated cells shows viable cells (anX-FITC-/PI-) (1), shows early apoptosis (anX-FITC+/PI-) (2), shows early apoptosis (anX-FITC-/anX-DOPA-DBCO+) (3), shows late apoptosis (anX-FITC+/PI+) (4) and shows late apoptosis (anX-FITC+/anX-DOPA-DBCO+) (5).

\section{Supplementary Files}

This is a list of supplementary files associated with this preprint. Click to download.

- floatimage1.png

- MolebioSupportinginformation.doc 